\section{SURFACE-ACTIVE AGENTS FROM THE GROUP OF POLYOXYETHYLATED GLYCEROL ESTERS OF FATTY ACIDS. PART IV. EQUILIBRIUM MICELLAR SOLUBILIZATION OF SELECTED LIPOPHILIC THERAPEUTIC AGENTS (BCS CLASS II AND III) IN AQUEOUS SOLUTIONS OF PRODUCTS OF CATALYTIC OXYETHYLATION OF TRIGLYCERIDE FRACTIONS EXTRACTED FROM PHARMACOPOEIAL LARD (ADEPS SUILLUS PP XI) OF $\mathrm{N}_{\mathrm{TE}} \geq 50$}

\author{
'Department of Drug Form Technology, Chair of Applied Pharmacy, \\ Medical University in Lodz, Poland \\ ${ }^{2}$ Department of Pharmacy, Chair of Applied Pharmacy, Medical University in Lodz, Poland \\ ${ }^{3}$ Higher School of Cosmetics and Health Sciences in Lodz, Poland
}

\begin{abstract}
Preformulation studies were carried out to estimate the solubilization capacity of products of catalytic oxyethylation of triglyceride fractions extracted from the pharmacopoeial lard (Adeps suillus, PP XI). There were determined basic viscosity $\left([\eta], M_{\eta}\right)$ and hydrodynamic $\left(R_{o}, R_{\text {obs }}, \Omega\right)$ values of micellar solutions of oxyethylated derivatives as well as their surface activity $-\gamma_{\mathrm{cmc}}^{25}$. Critical micellar concentration (cmc) was used to calculate the thermopotential for the formation of micelles $\left(\Delta \mathrm{G}_{\mathrm{m}}{ }^{\circ}\right)$. Model studies on micellar solubilization of gemfibrozil, loratadine and valsartan from the solid body surface (phase boundary) were performed under equilibrium conditions at the surfactant concentration of $c_{\exp }>>\mathrm{cmc}$. The amount of dissolved lipophilic therapeutic agents with qualitative and quantitative involvement of micellar solubilization was determined by spectrophotometric $(\mathrm{UV})$ method $-\mathrm{c}_{\mathrm{|s|}}(\mathrm{mg} / 100 \mathrm{~mL})$ as well as by calculating the solubilization indices $-\mathrm{n}_{\mathrm{|s|}}$ $(\mathrm{mol} / \mathrm{mol})$. The research study has identified structures of oxyethylated derivatives of triglyceride fractions which selectively and effectively solubilize gemfibrozil, loratadine and valsartan from the solid surface in the equilibrium system. The obtained results are a technological inspiration to create a model form of the drug (tablet) with continuous dispersion of lipophilic therapeutic agents (gemfibrozil, loratadine and valsartan), obtained on the basis of the liquefied surfactant structure.
\end{abstract}

Keywords: micellar solubilization, products of triglyceride fraction ethoxylation, gemfibrozil, loratadine, valsartan

In vitro determination of the solubilization capacity of bile "A" of the healthy and the sick (bile duct diseases) enabled to evaluate in vivo from the Lindblad dependence

$$
0.7[\mathrm{~mol} / \mathrm{mol}]=\frac{\Sigma \text { cholesterol }}{\Sigma \text { cholic acid } / \mathrm{Na}^{+}+\Sigma \text { lecithin }}
$$
the numerical value of the hydrophilic-lipophilic balance $\left(\mathrm{HLB}_{\mathrm{cmc}}\right)$, which determines the micellar solubilization of liquid crystal cholesterol and lipophilic therapeutic agents (1-3). The obtained results were an inspiration to undertake preformulation studies on non-ionic surfactants, products of catalytic oxyethylation found in bile " $\mathrm{A}$ " composition: cholic acid (4-6), urodeoxycholic acid (7) and cholesterol (8), which introduced as excipients into the model form of the drug with a lipophilic therapeutic agent should provide their micellar solubilization and high bioavailability due to the equilibrium process of mass exchange at the phase boundary.

Alternative structures that can improve the lithogenolytic index of bile "A" are products of catalytic oxyethylation of triglyceride fractions extracted from lard (Adeps suillus, PP XI) in the molecule

\footnotetext{
* Corresponding author: e-mail: zbigniew.marczynski@umed.lodz.pl
} 


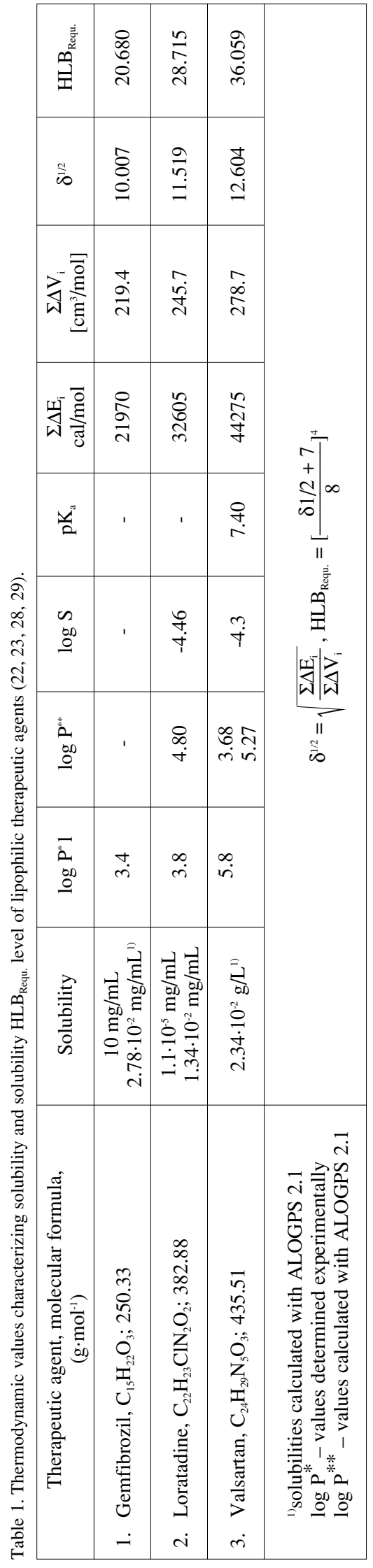

of which fatty acids are compatible with those analogous in the structure of lecithin $\alpha$ or $\beta$ (8-12).

Published results of studies on the process of equilibrium solubilization of lipophilic therapeutic agents (13-16) (BCS class II and IV), cholesterol and crushed (lipotrypsy) gallstones $(17,18)$ initiated the research on the products of catalytic oxyethylation of triglyceride fractions with ethylene oxide content $\mathrm{n}_{\mathrm{TE}}>50$ and on the micellar solubilization of selected lipophilic therapeutic agents - gemfibrozil, loratadine and valsartan $(19,20)$. These are therapeutic agents of extremely low solubility in water and body fluids.

Surface activity and solubilization capacity of the non-ionic class of surfactants were estimated in equilibrium system (saturated solutions) in relation to topologically complex, lipophilic therapeutic agents mentioned above (21-23).

Basic viscosity $\left([\eta], M_{\eta}\right)$ and hydrodynamic $\left(\mathrm{R}_{\mathrm{o}}, \mathrm{R}_{\mathrm{obs} .}, \Omega\right)$ values were determined for the micellar solutions of surfactants and their molecular adducts with lipophilic therapeutic agents.

The spectroscopic (UV) method was used to determine the amount of solubilized gemfibrozil, loratadine and valsartan in the equilibrium system in the environment of micellar surfactant solutions.

The obtained results allow producing model solid dosage forms, maintaining the standard API (Active Pharmaceutical Ingredient) lipophilic dose with the participation of an effective solubilizing surfactant. These allow estimating the pharmaceutical availability in relation to the reference market form of the medicinal product in model receptor fluids.

\section{EXPERIMENTAL}

\section{Material}

Biologically active substances (API)

1. Gemfibrozil; $\mathrm{C}_{15} \mathrm{H}_{22} \mathrm{O}_{3}$;

(2,2-dimethyl-5-[2,5-dimethylphenoxy] pentanoic acid, analytically pure

Sigma-Aldrich Fine Chemicals, G 9518

2. Loratadine, $\mathrm{C}_{22} \mathrm{H}_{33} \mathrm{ClN}_{2} \mathrm{O}_{2}$;

4-(8-chloro-5,6-dihydro-11H-benzo[5,6] cyclohepta [1,2-b] pyridin-11-ylidene)-1-piperidinecarboxylic acid ethyl ester analytically pure Zydus Cadila-Cadila Healtcare Ltd., India)

3. Valsartan, $\mathrm{C}_{24} \mathrm{H}_{29} \mathrm{~N}_{5} \mathrm{O}_{3}$

(2S)-3-methyl-2-[N-(\{4-[2-(2H-1,2,3,4-tetrazol-5 yl)phenyl]phenyl \}methyl) pentanamido] butanoic acid Aurobindo Pharma Ltd, India)

4. Products of catalytic oxyethylation of triglyceride fractions extracted from pharmacopoeial lard (Adeps suillus, PP XI) of $\mathrm{n}_{\mathrm{TE}} \geq 50$ : 


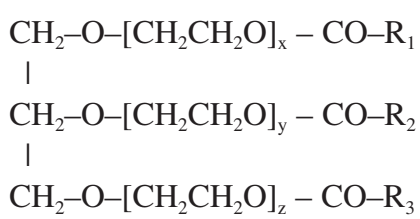

where: $\mathrm{x}+\mathrm{y}+\mathrm{z} \geq 50$ (24).

\section{Methods}

Basic physicochemical and thermodynamic quantities and the solubility parameter $-\delta^{1 / 2}$ as well as the solubility level of hydrophilic-lipophilic balance $\mathrm{HLB}_{\text {Requ. }}$ were calculated on the basis of the components of the general Hildebrand-Scatchard-Fedors solubility theory (22) and summarized in Table 1.

The technology of obtaining the structure of surfactants and their selected properties was discussed in publications (9-11). Selected physicochemical values characterizing the structure of nonionic surfactants are listed in Table 2.

The viscosity and surface tension of aqueous solutions of surfactants and adducts after equilibrium micellar solubilization were determined with a Ubbelohde dilution viscometer acc. to the Polish Standard (25).

The limiting viscosity number $[\eta$, GLL], for surfactant solutions and exposure concentrations solubilizing gemfibrozil, loratadine and valsartan in equilibrium were calculated from the equation:

$$
[\eta, \mathrm{GLL}]=\left[\eta_{\mathrm{sp} .}+3 \ln \left(\eta / \eta_{\mathrm{o}}\right)\right] / 4 \mathrm{c},
$$

which was the basis - analogically to publication (26) - for calculating viscosity $\left(\mathrm{M}_{\eta}, \mathrm{n}_{|\mathrm{s}|}\right)$ and hydrodynamic values $\left(\mathrm{R}_{\mathrm{o}}, \mathrm{R}_{\mathrm{obs}}, \Omega\right)$.

The surface tension of aqueous solutions of surfactants was determined by the stalagmometric method according to the Polish Standard (27).

The critical micellar concentration $(\mathrm{cmc})$ was determined as in publication (18), which allowed to calculate the thermodynamic potential of micelle formation $\left(\Delta \mathrm{G}_{\mathrm{m}}^{\circ}\right)$ from the dependence:

$$
\Delta \mathrm{G}_{\mathrm{m}}^{\mathrm{o}}=2.303 \mathrm{RT} \cdot \log \mathrm{cmc}
$$

The numerical value of the decrease of the surface tension coefficient in the critical area $-\gamma_{\mathrm{cmc}}^{25}$ was the basis for calculating from the dependence:

$$
\mathrm{f}(\pi) \cdot \mathrm{A}_{\mathrm{m}}=\mathrm{k} \cdot \mathrm{T}
$$

where: , transformed into an application form:

$$
A_{m}=\frac{k \cdot T}{\gamma_{c m c}^{55}-\gamma_{H_{2} O}^{25}}
$$

the "average area per one surfactant molecule at phase boundary". The minimal value $A_{m}$ for 1 molecule of the surfactant is about $20 \cdot 10^{-16} \mathrm{~cm}^{2}$. The obtained results characterizing aqueous solutions of nonionic surfactants are demonstrated in Table 3.

\section{Micellar solubilization of gemfibrozil, loratadine and valsartan in the equilibrium system}

The spectroscopic method was used, in analogy to publications $(6,7)$, to determine the amount of gemfibrozil, loratadine and valsartan lipophilic structures solubilized in equilibrium conditions in aqueous solutions of the surfactant.

Approximation equations at $\mathrm{p}=0.05$ :

for gemfibrozil:

$$
\begin{gathered}
\text { at } \lambda=274 \mathrm{~nm} \text { and } \mathrm{r}^{2}=0.9968, \\
\mathrm{~A}=0.0387+0.1706 \cdot \mathrm{c}
\end{gathered}
$$

and

$$
\begin{gathered}
\text { at } \lambda=279 \mathrm{~nm} \text { and } \mathrm{r}^{2}=0.9981, \\
\mathrm{~A}=0.0612+0.1556 \cdot \mathrm{c}
\end{gathered}
$$

for loratadine:

$$
\text { at } \begin{gathered}
\lambda=208 \mathrm{~nm} \text { and } \mathrm{r}^{2}=0.9951, \\
\mathrm{~A}=0.0796+1.7120 \cdot \mathrm{c}
\end{gathered}
$$

and

$$
\begin{gathered}
\text { at } \lambda=248 \mathrm{~nm} \text { and } \mathrm{r}^{2}=0.9918, \\
\mathrm{~A}=0.0340+0.7873 \cdot \mathrm{c}
\end{gathered}
$$

for valsartan:

$$
\begin{gathered}
\text { at } \lambda=251 \mathrm{~nm} \text { and } \mathrm{r}^{2}=0.9975, \\
\mathrm{~A}=0.1107+0.2794 \cdot \mathrm{c}
\end{gathered}
$$

describing the relationship between the API concentration (c, [mg/100 mL], methanol solutions) and the measured value of absorbance (A) after transforming the regression equations into the form:

Table 2. Selected physicochemical values of oxyethylated triglyceride fractions of lard (Adeps suillus PP XI).

\begin{tabular}{|l|c|c|c|c|c|c|c|}
\hline \multicolumn{1}{c|}{$\begin{array}{c}\text { Product of } \\
\text { oxyethylenation }\end{array}$} & $\begin{array}{c}\text { Declared } \\
\mathrm{n}_{\mathrm{TE}}\end{array}$ & $\begin{array}{c}\text { Calculated } \\
\text { Mol. weight }\end{array}$ & $\begin{array}{c}\text { Determined } \\
\mathrm{n}_{\mathrm{TE}}\end{array}$ & $\mathrm{M}_{\mathrm{w}}$ & $\mathrm{E} \%$ & \multicolumn{2}{c|}{ Calculated HLB } \\
\cline { 7 - 8 } 1. Friolehina FL6 & 50 & 3086.08 & 68.34 & 3869.99 & 77.79 & 16.25 & 15.56 \\
\hline 2. Friolehina 12i & 50 & 3062.06 & 64.59 & 3704.79 & 76.81 & 16.08 & 15.36 \\
\hline 3. Friolehina 12N & 50 & 3086.08 & 63.89 & 3697.97 & 76.11 & 16.02 & 15.22 \\
\hline 4. Curtoil & 50 & 3086.08 & 67.75 & 3844.00 & 77.64 & 16.17 & 15.53 \\
\hline 5. Frisol 37R & 50 & 3065.08 & 65.64 & 3754.06 & 78.05 & 16.02 & 15.61 \\
\hline 6. Frisol 50i & 50 & 3060.04 & 67.94 & 3850.35 & 77.73 & 16.24 & 15.55 \\
\hline
\end{tabular}




$$
c=\frac{A \cdot a}{b}
$$

allow to calculate the amount of solubilized therapeutic agent: gemfibrozil, loratadine and valsartan.

Obtained results were the basis for calculating the numerical value of the micellar partition coefficient - from the dependence:

$$
K_{w}^{m}=\frac{c_{|s|}-c_{\mid s / H_{2} O}}{c_{|s| H_{2} O}}
$$

The obtained results are presented in Tables 5, 6, 7 .

\section{RESULTS}

It results from the thermodynamic values presented in Table 1, characterizing the solubility of gemfibrozil, loratadine and valsartan in water, that they are practically insoluble, so undertaking research on their micellar solubilization in the equilibrium system in the environment of aqueous solutions of the oxyethylation products of lard fraction finds application and justification (11).

The content of oxyethylene segments in the surfactant molecule $\mathrm{n}_{\mathrm{TE}}\left(-\mathrm{OCH}_{2} \mathrm{CH}_{2}\right)$ calculated using the ${ }^{1} \mathrm{HNMR}$ method was the basis for estimating the structural level of hydrophilic-lipophilic balance HLB ( ${ }^{1}$ HNMR, Griffin methods), Table 2, the numerical value of which indicates significant surface activity and solubilization capacity at the phase boundary: solids (API) $\div$ micellar surfactant solution $(17,18)$.

The surface activity of aqueous solutions of oxyethylated triglyceride fractions was estimated by the stalagmometric method according to the Polish Standard (25), determining: critical micellar concentration $(\mathrm{cmc})$, thermodynamic potential of micelle formation $-\Delta \mathrm{G}_{\mathrm{m}}^{\mathrm{o}}$ and numerical value of lipophilic core upthrust of the surfactant $-\mathrm{A}_{\mathrm{m}}$ over the phase boundary: air $\div$ micellar surfactant solution $\left(\mathrm{c}_{\exp }>>\right.$ $\mathrm{cmc}$ ).

The values characterizing the micellar solution of the new class of nonionic surfactants are presented in Table 3.

The numerical value of $\Delta \mathrm{G}_{\mathrm{m}}^{\circ}$ for the tested surfactants is in the range $-20.6952 \mathrm{~kJ} / \mathrm{dm}^{3} \div-23.0459$ $\mathrm{kJ} / \mathrm{dm}^{3}$ and indicates a significant difference of the thermodynamic micellar lifetime of the colloid as

Table 3. Physicochemical values characterizing surface activity of aqueous solutions of products of oxyethylation of lard fractions (Adeps suillus PP XI).

\begin{tabular}{|c|c|c|c|c|c|c|}
\hline $\begin{array}{c}\text { Oxyethylation product, } \\
\text { solubilizer of } \mathrm{n}_{\mathrm{TE}}=50\end{array}$ & $\begin{array}{c}\mathrm{cmc} \\
{\left[\mathrm{g} \cdot 100 \mathrm{~cm}^{-3}\right]}\end{array}$ & $\begin{array}{c}\mathrm{cmc}^{*} \\
{\left[\mathrm{~mol} \cdot \mathrm{dm}^{-3}\right]}\end{array}$ & $\log \mathrm{cmc}$ & $\begin{array}{c}\Delta \mathrm{G}_{\mathrm{m}}^{\mathrm{o}} * \\
{\left[\mathrm{~kJ} \cdot \mathrm{dm}^{3}\right]}\end{array}$ & $\begin{array}{c}\delta_{c m c}^{25} \\
{\left[\mathrm{~mJ} \cdot \mathrm{m}^{-2}\right]}\end{array}$ & $* * \mathrm{Am}^{2} \cdot 10^{-20}\left[\mathrm{~m}^{2}\right]$ \\
\hline 1. Friolehina FL6 & 0.031409 & $1.0398 \cdot 10^{-4}$ & -3.9830 & -23.0459 & 51.43 & 20.0801 \\
\hline 2. Friolehina 12i & 0.039746 & $1.3475 \cdot 10^{-4}$ & -3.8704 & -22.0962 & 49.85 & 18.6010 \\
\hline 3. Friolehina 12N & 0.040641 & $1.8028 \cdot 10^{-4}$ & -3.7440 & -21.3746 & 49.47 & 18.2870 \\
\hline 4. Curtoil & 0.032993 & $1.2036 \cdot 10^{-4}$ & -3.9195 & -22.3765 & 50.63 & 19.2806 \\
\hline 5. Frisol 37R & 0.062084 & $2.3308 \cdot 10^{-4}$ & -3.6325 & -20.6952 & 61.14 & 37.9742 \\
\hline 6. Frisol 50i & 0.041494 & $1.3356 \cdot 10^{-4}$ & -3.8743 & -22.1185 & 52.69 & 21.3396 \\
\hline
\end{tabular}

Table 4. Selected viscosity values of aqueous solutions of non-ionic surfactants - products of oxyethylated lard fractions (Adeps suillus PP

\begin{tabular}{|c|c|c|c|c|c|c|c|}
\hline $\begin{array}{l}\text { Product of oxyethylenation, } \\
\text { solubilizer of } \mathrm{n}_{\mathrm{TE}}=50\end{array}$ & $\begin{array}{c}\operatorname{cexp} \\
{\left[\mathrm{g} \cdot 100 \mathrm{~cm}^{-2}\right]}\end{array}$ & $\eta$, GLL & $\mathrm{M}_{\chi}$ & $\begin{array}{c}\mathrm{R}_{\mathrm{o}} \cdot 10^{-7} \\
{[\mathrm{~cm}]}\end{array}$ & $\begin{array}{c}\mathrm{R}_{\mathrm{obs}} \cdot 10^{-8} \\
\quad[\mathrm{~cm}]\end{array}$ & $\begin{array}{c}\Omega \cdot 10^{-20} \\
{\left[\mathrm{~cm}^{3}\right]}\end{array}$ & 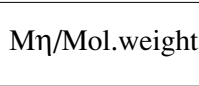 \\
\hline 1. Friolehina FL6 & 1.1127 & 0.113757 & 3020.66 & 4.6430 & 3.7909 & 2.2821 & 0.9788 \\
\hline 2. Friolehina $12 \mathrm{i}$ & 1.0805 & 0.112396 & 2949.76 & 4.5879 & 3.7459 & 2.2018 & 0.9633 \\
\hline 3. Friolehina $12 \mathrm{~N}$ & 1.0925 & 0.095328 & 2254.33 & 3.9705 & 3.2418 & 1.4272 & 0.7304 \\
\hline 4. Curtoil & 1.0655 & 0.107277 & 2741.12 & 4.4081 & 3.5991 & 1.9529 & 0.8882 \\
\hline 5. Frisol 37R & 1.1595 & 0.105435 & 2663.64 & 4.3410 & 3.5443 & 1.8651 & 0.8690 \\
\hline 6. Frisol 50i & 1.0571 & 0.115703 & 3106.67 & 4.7132 & 3.8482 & 2.3872 & 1.0152 \\
\hline
\end{tabular}
$\mathrm{XI})$. 
Table 5. Viscosity and hydrodynamic parameters characterizing equilibrium process of micellar solubilization of gemfibrozil.

\begin{tabular}{|c|c|c|c|c|c|c|c|c|}
\hline $\begin{array}{l}\text { Therapeutic agent: gemfibrozil, } \\
\text { solubilizer of } \mathrm{n}_{\mathrm{TE}}=50\end{array}$ & {$[\eta]$, GLL } & $\mathrm{M}_{\eta}$ & ${ }^{1)} n_{|\mathrm{s}|}$ & $\begin{array}{l}\mathrm{R}_{\mathrm{o}} \cdot 10^{-7} \\
{[\mathrm{~cm}]}\end{array}$ & $\begin{array}{l}\mathrm{R}_{\text {obs. }} \cdot 10^{-8} \\
\quad[\mathrm{~cm}]\end{array}$ & $\begin{array}{l}\Omega \cdot 10^{-20} \\
{\left[\mathrm{~cm}^{3}\right]}\end{array}$ & $\begin{array}{c}\mathrm{c}_{\mathrm{lsl}} \\
{\left[\mathrm{mg} \cdot 100 \mathrm{~cm}^{-3}\right]}\end{array}$ & 2) $\mathrm{K}_{\mathrm{w}}^{\mathrm{m}}$ \\
\hline 1. Friolehina FL6 & 0.143148 & 4419.16 & 5.5866 & 45.6904 & 4.6461 & 4.2011 & 39.0679 & 0.0471 \\
\hline 2. Friolehina $12 \mathrm{i}$ & 0.196319 & 7455.13 & 17.9977 & 7.5262 & 6.1449 & 9.7199 & 49.9120 & 0.3377 \\
\hline 3. Friolehina $12 \mathrm{~N}$ & 0.157144 & 5157.21 & 11.5962 & 6.1802 & 5.0461 & 5.3822 & 52.5498 & 0.4084 \\
\hline 4. Curtiol $\cdot \mathrm{n}_{\mathrm{TE}}=50$ & 0.138522 & 4185.25 & 5.7689 & 5.5273 & 4.5129 & 3.8502 & 39.3610 & 0.0549 \\
\hline 5. Frisol 37R & 0.198368 & 7584.38 & 19.6829 & 7.5957 & 6.2017 & 9.9917 & 77.7549 & 1.0841 \\
\hline 6. Frisol 50i & 0.136815 & 4100.24 & 3.9690 & 5.4670 & 4.4637 & 3.7255 & 44.3435 & 0.1885 \\
\hline \multicolumn{9}{|c|}{$\begin{array}{l}{ }^{1)} n_{\mathrm{lsl}}=\frac{M_{\eta \text { adductu }}-M_{\eta s o l}}{250.33} \\
{ }^{2)} \text { determined solubility of gemfibrozil in water at temp. } 25^{\circ} \mathrm{C}-c_{\mid s / H_{2} O}=37.3094\left[\mathrm{mg} \cdot 100 \mathrm{~cm}^{-3}\right]\end{array}$} \\
\hline
\end{tabular}

Table 6. Viscosity and hydrodynamic parameters characterizing equilibrium process of micellar solubilization of loratadine.

\begin{tabular}{|c|c|c|c|c|c|c|c|c|}
\hline $\begin{array}{l}\text { Therapeutic agent: loratadine, } \\
\text { solubilizer of } n_{\mathrm{TE}}=50\end{array}$ & {$[\eta]$, GLL } & $\mathrm{M}_{n}$ & ${ }^{11} \mathbf{n}_{\mathrm{tsl}}$ & $\begin{array}{l}\mathrm{R}_{0} \cdot 10^{-7} \\
{[\mathrm{~cm}]}\end{array}$ & $\begin{array}{c}\mathrm{R}_{\text {obs: }} \cdot 10^{-8} \\
{[\mathrm{~cm}]}\end{array}$ & $\begin{array}{l}\Omega \cdot 10^{-20} \\
{\left[\mathrm{~cm}^{3}\right]}\end{array}$ & $\begin{array}{c}\mathrm{c}_{\mid \mathrm{sl}} \\
{\left[\mathrm{mg} \cdot 100 \mathrm{~cm}^{-3}\right]}\end{array}$ & ${ }^{2)} \mathrm{K}_{\mathrm{w}}^{\mathrm{m}}$ \\
\hline 1. Friolehina FL6 & 0.121513 & 3369.16 & 0.9102 & 4.9221 & 4.0188 & 2.7188 & 17.7187 & 3.1642 \\
\hline 2. Friolehina $12 \mathrm{i}$ & 0.166071 & 5651.25 & 7.0557 & 6.4901 & 5.2991 & 6.2328 & 18.6714 & 3.3881 \\
\hline 3. Friolehina $12 \mathrm{~N}$ & 0.106643 & 2714.32 & 1.2013 & 4.3849 & 3.5802 & 1.9223 & 17.0837 & 3.0149 \\
\hline 4. Curtiol $\cdot \mathrm{n}_{\mathrm{TE}}=50$ & 0.166117 & 5653.83 & 7.6075 & 6.4916 & 5.3001 & 6.2374 & 20.0685 & 3.7164 \\
\hline 5. Frisol 37R & 0.165826 & 5637.45 & 7.7668 & 6.4816 & 5.2921 & 6.2084 & 18.6079 & 3.3732 \\
\hline 6. Frisol 50i & 0.126638 & 3607.66 & 1.3084 & 5.1054 & 4.1684 & 3.0341 & 18.6079 & 3.3732 \\
\hline \multicolumn{9}{|c|}{$\begin{array}{l}{ }^{1)} n_{\text {lst }}=\frac{M_{\text {nadductu }}-M_{\eta s o l}}{382.88} \\
{ }^{2)} \text { determined solubility of gemfibrozil in water at temp. } 25^{\circ} \mathrm{C}-c_{\mid s / H_{2} O}=4.2550\left[\mathrm{mg} \cdot 100 \mathrm{~cm}^{-3}\right]\end{array}$} \\
\hline \multicolumn{9}{|c|}{$K_{w}^{m}=\frac{c_{s s m i c}-c_{|s| H_{2} O}}{c_{s s / H_{2} O}}$} \\
\hline
\end{tabular}

Table 7. Viscosity and hydrodynamic parameters characterizing equilibrium process of micellar solubilization of valsartan.

\begin{tabular}{|c|c|c|c|c|c|c|c|c|}
\hline $\begin{array}{l}\text { Therapeutic agent: valsartan, } \\
\text { solubilizer of } \mathrm{n}_{\mathrm{TE}}=50\end{array}$ & {$[\eta]$, GLL } & $\mathrm{M}_{\eta}$ & ${ }^{1)} \mathrm{n}_{\mid \mathrm{sl}}$ & $\begin{array}{c}\mathrm{R}_{\mathrm{o}} \cdot 10^{-7} \\
{[\mathrm{~cm}]}\end{array}$ & $\begin{array}{l}\mathrm{R}_{\text {obs. }} \cdot 10^{-8} \\
\quad[\mathrm{~cm}]\end{array}$ & $\begin{array}{l}\Omega \cdot 10^{-20} \\
{\left[\mathrm{~cm}^{3}\right]}\end{array}$ & $\begin{array}{c}\mathrm{c}_{\mathrm{lsl}} \\
{\left[\mathrm{mg} \cdot 100 \mathrm{~cm}^{-3}\right]}\end{array}$ & 2) $\mathrm{K}_{\mathrm{w}}^{\mathrm{m}}$ \\
\hline 1. Friolehina FL6 & 0.172220 & 6001.86 & 6.8453 & 6.7023 & 5.4723 & 6.8646 & 66.4459 & 2.9374 \\
\hline 2. Friolehina $12 \mathrm{i}$ & 0.139604 & 4239.50 & 2.9614 & 5.5655 & 4.5441 & 3.9314 & 88.0995 & 4.2205 \\
\hline 3. Friolehina $12 \mathrm{~N}$ & 0.131719 & 3850.48 & 3.6650 & 5.2863 & 4.3162 & 3.3683 & 80.4044 & 3.7646 \\
\hline 4. Curtiol $\cdot \mathrm{n}_{\mathrm{TE}}=50$ & 0.143609 & 4442.75 & 3.9072 & 5.7066 & 4.6593 & 4.2372 & 110.4688 & 5.5461 \\
\hline 5. Frisol 37R & 0.148294 & 4685.30 & 4.6420 & 5.8711 & 4.7936 & 4.6143 & 167.0186 & 8.8971 \\
\hline 6. Frisol 50i & 0.16618 & 5653.90 & 5.8488 & 6.4917 & 5.3001 & 6.2374 & 208.8403 & 11.3754 \\
\hline 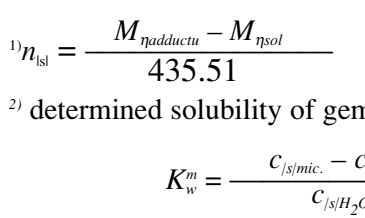 & brozil in w & ater at tem & p. $25^{\circ} \mathrm{C}$ & $c_{/ s / H_{2} O}=$ & $5.8754[\mathrm{n}$ & $100 \mathrm{~cm}^{-3}$ & & \\
\hline
\end{tabular}


well as the potential adduct with a lipophilic therapeutic agent.

The solubilization preferences of the micellar colloid at the phase boundary are confirmed by the numerical value of the decrease of the surface tension coefficient in the critical area $-\gamma_{\mathrm{cmc}}^{25}\left(\mathrm{~mJ} / \mathrm{m}^{2}\right)-$ Table 3, the numerical values of which are within the physiological standard, i.e. $48.0-52.0 \mathrm{~mJ} / \mathrm{m}^{2}$.

The research results indicate that the aqueous solution of the surfactant Frisol $37 \mathrm{R} \cdot \mathrm{n}_{\mathrm{TE}}=50$ is characterized by the numerical value $\gamma_{\mathrm{cmc}}^{25}=61.14$ $\mathrm{mJ} / \mathrm{m}^{2}$, which is greater than the physiological standard. At the same time, it corresponds to the highest numerical value $-\Delta \mathrm{G}_{\mathrm{m}}^{\mathrm{o}}=-20.6952 \mathrm{~kJ} / \mathrm{dm}^{3}$ in the series of homologous structures of oxyethylated derivatives.

Basic viscosity and hydrodynamic values of exposure solutions, in the environment of which the solubilization process of gemfibrozil, loratadine and valsartan was carried out are demonstrated in Table 4.

The determined limiting viscosity numbers

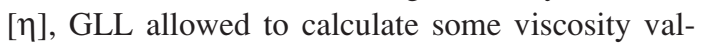
ues: mean molecular weight $-\mathrm{M}_{\eta}$ and hydrodynamic values $-R_{o}, R_{o b s}$ and $\Omega$, which were the basis for estimating the quantitative course of equilibrium solubilization of lipophilic therapeutic agents.

The obtained results are presented: for gemfibrozil - Table 5, loratadine - Table 6 and valsartan - Table 7.

The determined real solubility $-\mathrm{c}_{\mathrm{|s|}_{2} \mathrm{O}}$ of gemfibrozil, loratadine and valsartan (in $\mathrm{mg} / 100 \mathrm{~cm}^{3}$ ) enabled to calculate the equilibrium micellar partition coefficient - for saturated solution at $25^{\circ} \mathrm{C}$.

It results from the values of the equilibrium solubilization process of gemfibrozil presented in Table 5, that the calculated solubilization indices have been confirmed by the quantitative determination of the solubilized therapeutic agent - (mg/100 $\mathrm{cm}^{3}$ ) as well as by the micellar partition coefficient. Gemfibrozil in the technological degree of disintegration is most effectively solubilized in the environment of aqueous micellar solutions of surfactants of $\mathrm{n}_{\mathrm{TE}}=50$, in the following order: Frisol 37R > Friolehina $12 \mathrm{~N}>$ Friolehina $12 \mathrm{i}$.

The process of micellar solubilization of loratadine proceeds in similar conditions in the environment of aqueous solutions of surfactants - Table 6. It is significantly effective, which is confirmed not only by the molar solubilization coefficients but also by the amount of solubilized therapeutic agent - and the micellar partition coefficient.

Similarly, as in the case of gemfibrozil, loratadine is most effectively solubilized in aqueous micellar surfactant solution with $\mathrm{n}_{\mathrm{TE}}=50$ : Curtiol > Friolehina 12i > Frisol 37R and Frisol 50i.

The research results have shown that topologically complex structure of valsartan is solubilized quantitatively significantly in micellar solution of surfactants of $\mathrm{n}_{\mathrm{TE}}=50$, as evidenced by the determined molar solubilization coefficients and, above all, the amount of solubilized therapeutic agent $\left(\mathrm{mg} / 100 \mathrm{~cm}^{3}\right)$ and micellar partition coefficient $\mathrm{K}_{\mathrm{w}}^{\mathrm{m}}$.

Due to the unsaturated fatty acids contained in the triglyceride molecule (cis $\div$ trans isomerism), the topological structure of the surfactant micelles makes them present specific solubilizing preferences in relation to the lipophilic API structure in the aqueous solution. For this reason, the equilibrium solubilization of valsartan in the technological degree of disintegration (solubilization at the phase boundary: solid-phase $\div$ micellar surfactant solution) runs effectively quantitatively in relation to the real solubility determined at $25^{\circ} \mathrm{C}\left(\mathrm{mg} / 100 \mathrm{~cm}^{3}\right)$. The multiplicity of real solubility was recorded for equilibrium solubilization of valsartan by micellar solutions respectively: Frisol 50i > Frisol 37R > Curtiol, $\mathrm{n}_{\mathrm{TE}}=50$.

The obtained results indicate significant and unique solubilization capacity of the catalytically oxyethylated lard fractions in the structure of which there are unsaturated fatty acids compatible with those found in the structure of lecithin $\alpha$ and $\beta$.

\section{CONCLUSIONS}

1. Catalytically oxyethylated triglyceride fractions extracted from pharmacopoeial lard (Adeps suillus PP XI) in an aqueous solution of the concentration $c_{\exp } \gg c$ cmc, (Table 5, 6, 7) are characterized by significant solubilizing capacity in relation to lipophilic therapeutic agents: gemfibrozil, loratadine and valsartan.

Viscosity $\left(\eta, M_{\eta}\right)$ and hydrodynamic $\left(R_{o}, R_{o b s}\right.$, $\Omega$ ) values determined after equilibrium solubilization confirm that the process of molecular solubilization thermodynamically is an emanation of adsorption in the palisade layer of the micelle. This situation - with the molecular disintegration of the therapeutic agent in the micelle structure - will be conducive to an effective process of mass exchange at the phase boundary.

2. Oxyethylated derivative Frisol $37 \mathrm{R} \cdot \mathrm{n}_{\mathrm{TE}}=50$ appeared to be a universal structure for the quantitative course of the solubilization process. Its micelles in the equilibrium system - 
in relation to the routinely applied dose of the therapeutic agent increase the solubility of valsartan to $167.01 \mathrm{mg} / 100 \mathrm{~cm}^{3}$ (therapeutic dose $80-160 \mathrm{mg}$ tablet), loratadine to $167.01 \mathrm{mg} / 100$ $\mathrm{cm}^{3}$ (therapeutic dose $10 \mathrm{mg}$ tablet) and gemfibrozil to $72.75 \mathrm{mg} / 100 \mathrm{~cm}^{3}$ (therapeutic dose 300-450 mg tablet).

3. Owing to micellar solubilization, the solubility of loratadine increases most effectively $\left(\Sigma \Delta \mathrm{V}_{\mathrm{i}}=\right.$ $245.7 \mathrm{~cm}^{3} / \mathrm{mol}$, Table 1) in the environment of the solution of Curtoil $\cdot \mathrm{n}_{\mathrm{TE}}=50$; the determined equilibrium $c_{\mid \mathrm{sl}}=20.0685 \mathrm{mg} / 100 \mathrm{~cm}^{3}$, Table 6 , at routinely applied dose in the oral dosage form $10 \mathrm{mg}$ in one tablet.

4. The highest increase of valsartan solubility $\left(\Sigma \Delta \mathrm{V}_{\mathrm{i}}=278.7 \mathrm{~cm}^{3} / \mathrm{mol}\right)$ was observed in the environment of micellar solution of Frisol 50i . $\mathrm{n}_{\mathrm{TE}}=50$; the determined equilibrium $\mathrm{c}_{\mathrm{Isl}}=$ $208.8403 \mathrm{mg} / 100 \mathrm{~cm}^{3}$, Table 7 , at routinely applied dose in the oral dosage form $80-160 \mathrm{mg}$ in one tablet.

5. The obtained results are an inspiration for the technological modification of a solid oral dosage form containing gemfibrozil, loratadine and valsartan by introducing into the tablet mass a continuous dispersion of API in appropriately selected oxyethylated triglyceride fraction derivative extracted from lard (Adeps suillus, PP XI).

\section{Acknowledgments}

Financial support by a grant (503/3-02102/503-31-001 from the Medical University of Lodz, Poland is gratefully acknowledged.

\section{REFERENCES}

1. Zgoda M.M., Karczewski T.: Diagn. Lab. 29, 163 (1993).

2. Zgoda M.M., Karczewski T.: Acta Pol. Pharm. 47, 61 (1990).

3. Natalini B., Sardella R., Gioiello A., Ianni F., Di Michele A. et al.: J. Pharm. Biomed. Anal. 87, 62 (2014).

4. Zgoda M.M., Nachajski M.J., Kołodziejczyk M.K., Woskowicz M.H., Lukosek M.: Polim. Med. T. XXXVII, 21 (2007).

5. Kołodziejczyk M.K., Nachajski M.J., Lukosek M., Zgoda M.M.: Acta Pol. Pharm. 70, 1065 (2013)

6. Kołodziejczyk M.K., Nachajski M.J., Lukosek M., Zgoda M.M.: Acta Pol. Pharm. 71, 119 (2014).
7. Zgoda M.M., Lukosek M., Nachajski M.J.: Polim. Med. T. XXXVI, 13 (2006).

8. Zgoda M.M., Nachajski M.J., Kołodziejczyk M.K., Woskowicz M.H.: Polim. Med. T. XXXVII, 39 (2007).

9. Nachajski M.J., Kołodziejczyk M.K., Kołodziejska J., Lukosek M., Kosno J. et al: Przem. Chem. 92, 1815 (2013).

10. Piotrowska J.B., Nachajski M.J., Lukosek M., Zgoda M.M.: Polim. Med. 40, 27 (2010).

11. Piotrowska J.B., Nachajski M.J., Lukosek M., Zgoda M.M.: Polim. Med. 41, 53 (2011).

12. Johansson I., Svensson M.: Curr. Opin. Colloid Interface Sci. 6, 178 (2001).

13. Upponi J.R., Jerajani K., Nagesha D.K., Kulkarni P., Sridhar S. et al.: Biomaterials 170, 26 (2018).

14. Deshmukh A.S., Chauhan P.N., Noolvi M.N., Chaturvedi K., Ganguly K. et al.: Int. J. Pharm. 532, 249 (2017).

15. Lu Y., Park K.: Int. J. Pharm. 453, 198 (2013).

16. Mu M., Konno T., Inoue Y., Ishihara K.: Colloids Surf. B. 158, 249 (2017).

17. Nachajski M.J., Piotrowska J.B., Kołodziejczyk M.K., Lukosek M., Zgoda M.M.: Acta Pol. Pharm. 70, 547 (2013).

18. Kosno J., Lukosek M., Fischer R., Zgoda M.M., Nachajski M., Kołodziejczyk M.: The method of cholesterol solubilization; A1(21), 410769 (22) 2014, 12, 23; Bulletin of the Patent Office, 2016, 14 (1109), 8 (in Polish).

19. Kosno J., Lukosek M., Fischer R., Zgoda M.M., Nachajski M., Kołodziejczyk M.: The method of solubilization of gall stone cholesterol; A1(21), 410766 (22) 2014, 12, 23, Bulletin of the Patent Office, 2016, 14 (1109), 8 (in Polish).

20. Bustamante P., Navarro-Lupion J., Escalera B.: Eur. J. Pharm. Sci. 24, 229 (2005).

21. Folmer B.M.: Advances Coll. Interface Sci. 103, 99 (2003).

22. Wiedmann T.S., Kamel L.: J. Pharm. Sci. 91, 1743 (2002).

23. Zgoda M.M., Hreczuch W., Woskowicz M., Nachajski M., Kołodziejczyk M.: Polimery 48, 365 (2003).

24. Zgoda M.M., Woskowicz M., Nachajski M., Kołodziejczyk M., Lukosek M. et al.: Polimery 50, 873 (2995).

25. Polish Standard - PN-53/C-8930. Plastics. Principles of normalization of methods for determining the viscosity number and limiting viscosity number of polymers in dilute solutions. Official Standards and Measures No: 3/1993, item 5 (in Polish). 
26. Zgoda M.M., Nachajski M., Woskowicz M., Lukosek M.: Polim. Med. 34, 31 (2004).

27. Polish Standard - PN-90/C-04809. Surface active agents. Determination of surface tension $\left(\gamma_{\mathrm{s}}\right)$ and inter-phase tension $\left(\gamma_{\mathrm{i}}\right)$, Official Standards and Measures No: 2/1991, item. A (in Polish).
28. Fedors R.T.: Polymer Engin. Sci. 14, 147 (1974).

29. Wishart D.S., Knox C., Guo A.C., Cheng D., Shirivastave S. et al.: Nucleic Acid Res. 36, 901 (2008).

Received: 24.11 .2018 